\title{
THE SEMI- AUTOMATIC TRANSPLANTER OF SUGAR BEET
}

\author{
Ismail, Z. E.* and A. S. Ghattas**
}

\begin{abstract}
The aim of the present study has been concerned with a particular problem, associated with the sugar beet seedling transplanting. That aim was seen to be achieved through developing a transplanting machine with feeding system of the elastics disc which its idea depend on using the horizontal belt feed to vertical belt instead of using control guide. The general trend of this investigated that face the problem of little germination of sugar beet seeds in salted lands by using the seedling transplantation, and to control the row spacing in field. Under forward speed of $0.4 \mathrm{~m} / \mathrm{s}$, the best results were obtained using feeding metering speed of $0.16 \mathrm{~m} / \mathrm{s}$. The theoretical distance was $29.5 \mathrm{~cm}$ and the actual distance was $32.45 \mathrm{~cm}$. This was acceptable result as it was in the right limit (the interference is 10\%). while by changing the seedling location from 7.0 to $10 \mathrm{~cm}$ to the highest value of seedling dispersion $10.3 \%$ was obtained under forward speed of $1.16 \mathrm{~m} / \mathrm{s}$ with metering speed of $35 \mathrm{rpm}$. The maximum field efficiency of $94.5 \%$ was obtained at forward speeding of $1.5 \mathrm{~km} / \mathrm{h}$ and the minimum field efficiency of $83.2 \%$ was obtained at forward speed of $4.2 \mathrm{~km} / \mathrm{h}$.
\end{abstract}

\section{INTRODUCTION}

ugar beet (Beta vulgaris, L.) is an important crop not only in Egypt but also all over the world as a source of sugar, it is the second crop after sugar cane in Egypt in this respect. During 2005 season, the total cultivated area of sugar beet in Egypt reached up to $167390 *$ feddan, with an average production of 21.68 ton per fed. (F.A.O. Statistics, 2006). Strategic decision has been taken to increase the planted area of sugar beet in Dakahlia and Fayium Governorates as well as Nobaria region in an attempt to narrow the gab in sugar commodity.

*Professor of power technology and farm machinery Agric. Engineering department Faculty of Agric. Mansoura University Mansoura Egypt.

** Higher studies( Ph.D.) Agric. Engineering department Faculty of Agric. Mansoura University Mansoura_Egypt. 
The importance of this crop is not only limited at being a supplement for sugar production, but it also extends to the use of it as by products in producing untraditional animal food, as well as many other secondary industries .Therefore, the government is planning to increase the growing area of sugar beet and improving the technique of agricultural processes.

There are two common types of transplanting systems presently available to the farmers, which are manual and mechanical transplanting. Hand transplanting is arduous work, slow process and need consuming more labors than any other operation in vegetable planting (Saleh, 1990)

The advantages of mechanical transplanting are place seeding more uniform than manual transplanting. The uniformity of placing seedlings by the mechanical transplanting attributed to the transplanting mechanism design more than the operation condition. Ground speed of $0.9 \mathrm{~km} / \mathrm{h}$ was suitable for operating the mechanical transplanting (Harb et al., 1993).

Many investigations evaluated the factors affecting the vegetables seedling transplanting performance such as: shape and size of seedling, tall soil block around the seedlings root,the diameter of block and the old of seedling grown in soil block as indicated by many researchers, Tamatsu (1982); Saleh (1990); and Mortada, (2002).

Harb et al. (1993) indicated that the advantages of mechanical transplanting are place seeding more uniform than manual transplanting. And he added that the uniformity of placing seedlings by the mechanical transplanting attributed to the transplanting mechanism design more than the operation condition. Ismail and El shekha (1989) describe the theoretical feeding position of seedling from inertia point to level of seed the seedling in the soil. They added that ground speed of $0.9 \mathrm{~km} / \mathrm{h}$ was suitable for operating the mechanical transplanting.

The multiple loading feature mechanism significantly increased the operator speed because it allowed up to five plants to be fed into the mechanism before they are actually needed. One operator on the machine with multiple loading stations could transplant at the same rate (about 70 to $80 \mathrm{plant} / \mathrm{min}$ ) as two operators on conventional one-row machine. While Hamad et al. (1983) reported that the seeding damage faulty in planting and feeding losses increased due to increasing transplanter forward speed. 
In report of ASAE (1989) and Odigbah and Akubuo (1991) found that the field efficiency decreased by increasing forward speed. Also, Helmy et al. (2000) found that the sugar yield (and root yield) of sugar beet decreased from about 4.5 to $3.5 \mathrm{Mg} / \mathrm{fed}$ by increasing Holland transplanter forward speed from 0.95 to $3.65 \mathrm{~km} / \mathrm{h}$ respectively.

Two major problems prevented its use in transplanting sugar beet seedling. First, sugar beet seedlings at transplanting time have a larger spread of root area than other seedling. Dropping sugar beet seedlings through a tube under suction pressure could easily damage their fragile root. Second, any degree of root damage prevent to low size of beet and more divergence in root body.

There fore the aim of our work are:-

1- Investigated the feeding system have the ability to transplant the sugar beet seedling

2- Studies the parameters affecting the transplanting performances.

\section{MATERIALS AND METHODS}

The new investigated of transplanter machine must be meeting the following requirements to transplant the sugar beet seedling: Seedling should be planted perpendicular to the soil without roots being unduly curved (max. permissible deviation from the vertical of plants grounded should not exceed $3 \%$ ); planting should be done at the required depth $(15-20 \mathrm{~cm})$ depending on the size of seedling bulb $( \pm 2 \mathrm{~cm})$; deviations from required spacing between seedlings in row should not exceed that $10 \%$ and No damage to seedling in planting (maximum up to $1.0 \%$ ); To utilize these conditions the main descriptions of the proposed design are:-

\section{1- The feeding unit}

1-1-The Seedling System, the seedlings are manually placed in a horizontal belt in a certain distance by the operators. As shown in Fig. (1), the two pulleys with dimensions of $10 \mathrm{~mm}$ diameter and width of $220 \mathrm{~mm}$ are connected with the transplanter frame. The distance between the two pulleys center is $700 \mathrm{~mm}$ and with belt width of $200 \mathrm{~mm}$. The driver pulleys take the motion from the transmission system, which transmits the power from press wheels (land wheel). And also it designed the functioning of cloth 
(belt) suitable for the transplant sugar beet moves on two axes and ball bearing.

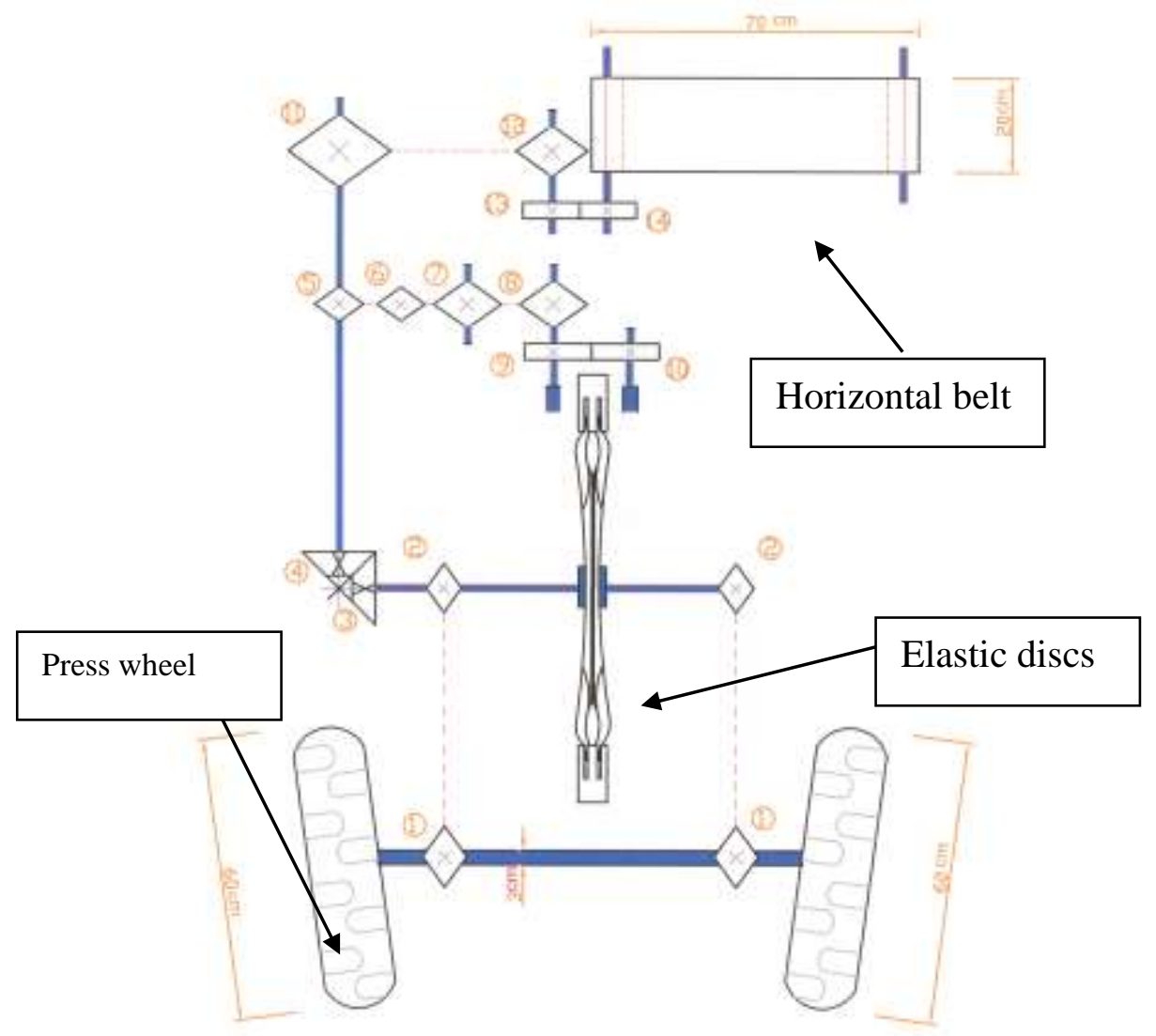

Fig. (1): The general layout of transplanting machine

1-2-Vertical conveyor, It has two vertical belts as shown in Fig. (2). the interactions in space between the two vertical belts help the seedling to convey from the highest contact level to the lower point. Then, the seedling drops between the elastic discs. To keep a good contact between the seedling and vertical belts and to overcome the seedling inclination, the vertical belts are supplied with elastic excessive 
1-3-Elastic disc, two elastic discs, $520 \mathrm{~mm}$ in diameter and $0.3 \mathrm{~mm}$ thickness, are inclined toward a vertical plane of an angle of $22^{\circ}$. Spacing between the disc center amount to $45 \mathrm{~mm}$, the length of the discs contact arc is $380 \mathrm{~mm}$. The two discs are driven by two gears on the press wheel. The transmission system from press wheel to the elastic discs is as shown in Fig. (3). The discs lie flat against each other at the front but are kept apart at the rear by small rollers press which enable a plant to be placed up sidedown between the tops of the discs just before they meet and to be planted in the ground when the discs move apart.
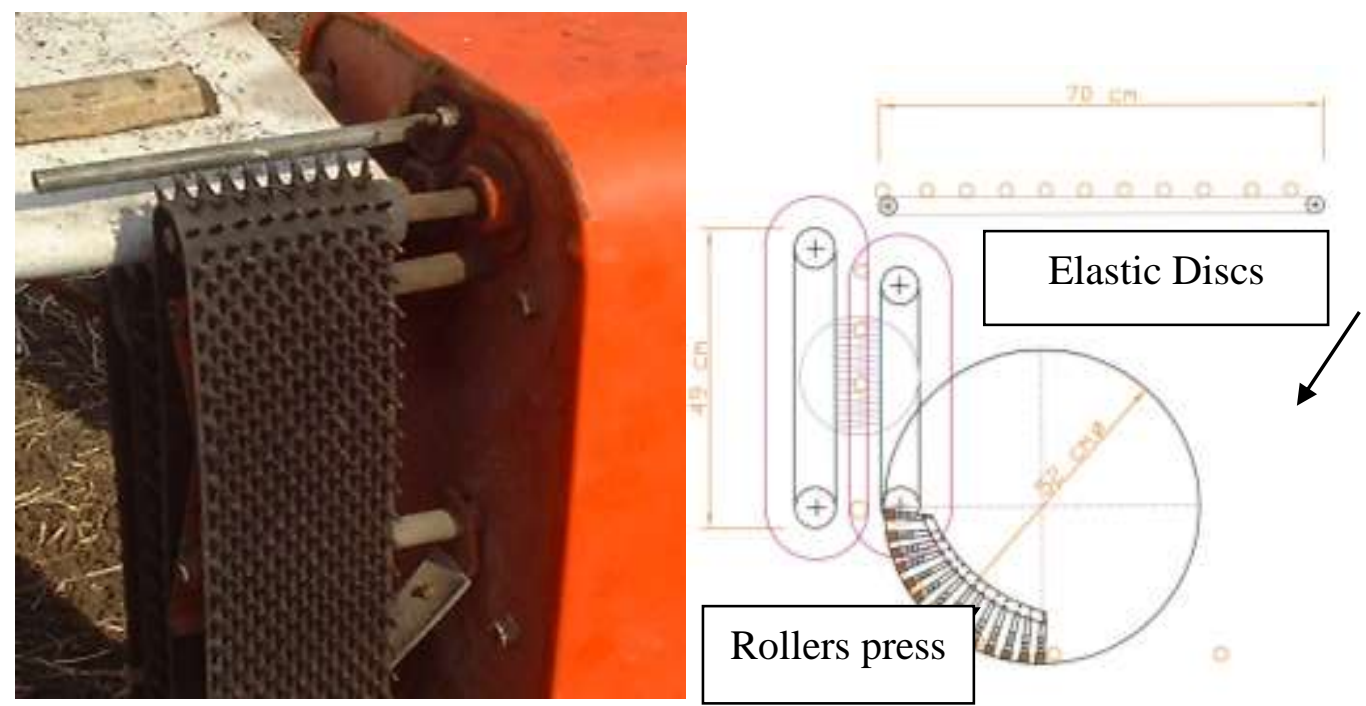

Fig. (2): A two vertical belts Fig. (3): The elastic discs and small rollers press

1-4- Press wheels, the elastic discs are driven by the two press wheel with diameter of $600 \mathrm{~mm}$ and width of the wheel rim is $60 \mathrm{~mm}$. They are inclined to the horizontal motion with angles to press the soil around the seedlings. In the event of a momentary difference in the slipping of the right and the left hand press wheel, due to a difference in adherence to the soil, even a slight jumping of the plant in between the discs produces a stretching of the helical belt and the speed of the left-hand disc becomes equal to that of the right-hand. 


\section{2- The Secondary Units}

2-1- cart holding seedling, hopper, and boxes is located on platforms, which seedlings are removed manually into transplanting device.

2-2-furrow opener, the frame is attached a furrow opener, the number of furrow depending on the transplanter unit. The shape of openers is such that they form a furrow with cross section approximating a rectangle. The used furrow opener is shaped at that the furrow shape formed, the depth of the furrow is about $200 \mathrm{~mm}$ and the width is $150 \mathrm{~mm}$. The furrow openers are usually employed, while a pair of press wheels tilted outward at the top accomplishes furrow closing and soil fir.

2-3- Coverers units, it is consists of two units, namely, close discs and two rollers which formed the furrow.

The Seedling Preparation: Sugar beet "Helna-variety" of mono-germs seeds was planted in paper-pot, which it set in $15 \mathrm{~cm}$ length for two sizes diameters "2.5 and $4 \mathrm{~cm}$ ". The seedlings were prepared in $22^{\text {ed }}$ August 2005 and in $25^{\text {Th }}$ November 2006. A nursery was irrigated weekly. Sugar beet seeds grew after a week.

The Variables Parameters: For optimization of the affecting performance of investigated transplanter, experiments were conducted with three transplanter traveling speeds of $0.4 ; 0.8$ and $1.16 \mathrm{~m} / \mathrm{s}$. the seedling location on the horizontal belt are 5,7 and $10 \mathrm{~cm}$ which realizing the distance between seedling in row of 15,21 and $30 \mathrm{~cm}$. the number of the rubber disc of 21.4; 29.8; and $36.69 \mathrm{rpm}$. The transmitted systems ratio between the revolution numbers of rubber disc and the press wheel is regulated to keep the ratio between seed space and seedlings dropping from transplanting device synchronize. The clearance between the feeding rubber discs is regulated by the roller press diameters therefore; three levels of roller press diameter of 15,18 and $21 \mathrm{~mm}$ are used. The last variables parameters are the size or diameters of paper pot diameters, two parameters of 2.5 and $4 \mathrm{~cm}$ are recommended by the authors. The tests were replicated three times for each treatments of transplanter.

Source of Power: the experimental lab is conducted by providing the investigated transplanter with a lathe as a source of power. The power 
transported from lathe to press wheel shaft through two pulleys and belt, which converted the rotating speed with group of gears.

\section{Seedling Miss Index (Sm, \%)}

The seedling miss index could be considered as the seedling disposing performance. It was estimated for each treatment by counting the number of location that have no seedlings and counting the total number of the seedling in each treatment. Then the percentage of miss index can be calculated as follows (Srivastava, 1995):

$$
S m, \%=\frac{B_{n}}{M} * 100
$$

Where:

$\mathrm{S}_{\mathrm{m}}=$ The percentage of seedling miss index, \%

$\mathrm{M}=$ The total number of the used seedling.

$\mathrm{B}_{\mathrm{n}}=$ The number of seed location that have no seedling.

\section{The seedlings multiples index, $\left(\mathrm{S}_{\mathrm{mu}} \%\right)$}

The seedling double ratio could be considered as the second indicator for the seedling disposing performance. It was estimated for each treatment by counting the number of holes that have more than one seedling and counting the number of the total seedling in each treatment. Then the percentage of seedlings multiples index can be calculated as follows:

$$
S_{m u}, \%=\frac{A_{n}}{M} * 100
$$

Where:

$S_{m u}, \%=$ the percentage of seedlings multiples index, $\%$

$\mathrm{A}_{\mathrm{n}} \quad=$ the number of holes that have more than one seedlings.

\section{The quality of feed index (UH, \% )}

The uniformity of the seedling in row could be considered as the third indicator for the seed disposing performance. It was estimated by calculating the seed miss index and the seed multiples index. Then the percentage of the quality of feed index in row can be calculated as follows:

$$
U H, \%=100-(S m, \%+S m u, \%)
$$




\section{The amount of seedling rate $(Q$, seedling/s)}

The actual amount of seedling rate (Ismail, 2004) was measured according to the equation of

$$
Q=\frac{M_{1} \times 100}{\psi}, \quad \text { Seedling } / s
$$

Where:

$\mathrm{M}_{1}$ : The number of seedling out from devices per certain times, dimensionless

$\Psi$ : The theoretical seedling numbers, dimensionless

The static analyses: The data were statistically analyzed to determine the effect of the traveling speed of transplanter under two different of the paper pot diameters $(2.5$ and $4.0 \mathrm{~cm})$ on performance indices. Namely, mean seed spacing, miss and multiples indexes, quality of feed index, precisions in spacing and the amount of seed rate. The ASA programming was used to analyses the obtained data under different variables.

\section{RESULTS AND DISCUSSION}

The performance of developed seedling device for transplanting sugarbeet was tested and evaluated according to the following criteria: Seedlings longitudinal dispersion; seedlings lateral dispersion; and the quality of seedling index.

\section{1- Effect of transplanter speed $(\mathrm{m} / \mathrm{s})$ on the longitudinal dispersion}

Figs from (4) and (5) illustrate the relationship between forward speed and means of distance between seedlings under different metering speeds on longitudinal dispersion for sugar beet seedlings. General trends clearly revealed that, the longitudinal dispersion is directly proportional to forward speed (V), and also it is directly proportional to the roller press diameter (Pr). From mentioned Figs, under forward speed of $0.4 \mathrm{~m} / \mathrm{s}$ with different roller press diameters of $15 ; 18$ and $21 \mathrm{~mm}$ were 28.85, 35.23 and $53.81 \mathrm{~cm}$ respectively. By increasing forward speed to $0.8 \mathrm{~m} / \mathrm{s}$ the actual distances were $42.25,37.3$ and $40.16 \mathrm{~cm}$, respectively. With changing forward speed to $1.16 \mathrm{~m} / \mathrm{s}$. the distances were $38.1,40.45$ and $49.95 \mathrm{~cm}$ respectively. These results were with theoretical distances of 29.29; 39.95 and $42.83 \mathrm{~cm}$. All previous results were under using paper pot diameter of $2.5 \mathrm{~cm}$ and at the same forward speed of feeding disc of 
22rpm. There was approximately similarity between both theoretical and actual distances. As actual distances ranged from $38 \mathrm{~cm}$ (the highest limit) to $18 \mathrm{~cm}$ (the lowest limit) while sugar beet originally transplanting seedling on $20-25 \mathrm{~cm}$ distance intervals, the theoretical distances ranged from 35 to $20 \mathrm{~cm}$. Under forward speed of 0.4 , the best results were obtained by using feeding metering speed of $0.16 \mathrm{~m} / \mathrm{s}$. The theoretical distance was $29.5 \mathrm{~cm}$ and the actual distance was $32.45 \mathrm{~cm}$. This was acceptable result as it was in the right limit (the interference is 10\%). Under paper pot of $4.0 \mathrm{~cm}$, the same trend was found. For example, with forward speed of $1.16 \mathrm{~m} / \mathrm{s}$ accompanied by feeding metering speed of $0.20 \mathrm{~m} / \mathrm{s}$, the acceptable result of $35.5 \mathrm{~cm}$ actual distance with $25.4 \mathrm{~cm}$ theoretical distance was obtained. Also, feeding metering speed of 0.25 $\mathrm{m} / \mathrm{s}$ gave a relative result. On the other hand, actual distance of $35.9 \mathrm{~cm}$ with theoretical distance of $21.6 \mathrm{~cm}$ was obtained under feeding metering speed of $0.25 \mathrm{~m} / \mathrm{s}$ and forward speed of $1.16 \mathrm{~m} / \mathrm{s}$. Finally, using forward speed of $0.75 \mathrm{~m} / \mathrm{s}$ and metering speed of $0.16 \mathrm{~m} / \mathrm{s}$ gave the best results in all treatments with sugar beet.

Generally, any increment of forward speed resulted in increment of longitudinal dispersion (directly proportion) with paper pot of 2.5 or 4.0 $\mathrm{cm}$. These results were logical as increasing forward speed led to and increase of machine vibration and consequently seedlings through feeder tube dispersed. This vibration and skipping had to disperse seedlings on the surface of soil especially with higher forward speeds.

The equations of seedling location on the average distance between seedling in row at different roller press diameters are:-

$$
\begin{array}{lll}
\mathrm{y}=0.0449 \mathrm{x}^{2}-1.4805 \mathrm{x}+49.306 & \mathrm{R}^{2}=1 \quad \text { at roller press, } 15 \mathrm{~cm} \\
\mathrm{y}=0.0226 \mathrm{x}^{2}-0.0358 \mathrm{x}+22.548 & \mathrm{R}^{2}=1 \quad \text { at roller press } 18, \mathrm{~cm} \\
\mathrm{y}=0.0338 \mathrm{x}^{2}-0.8767 \mathrm{x}+31.064 & \mathrm{R}^{2}=1 \quad \text { at roller press } 21 \mathrm{~cm}
\end{array}
$$

\section{2- Effect of seedling location on the seedlings dispersion, \%}

The seedling location on the horizontal belt is considered as the primary factors affecting on the plant distribution as shown in figure 5 and 6. Data and figures showed that there was a directly proportion among the used parameters throughout the treatments. Obviously, the increment of forward speed resulted in increasing seedling dispersion. 


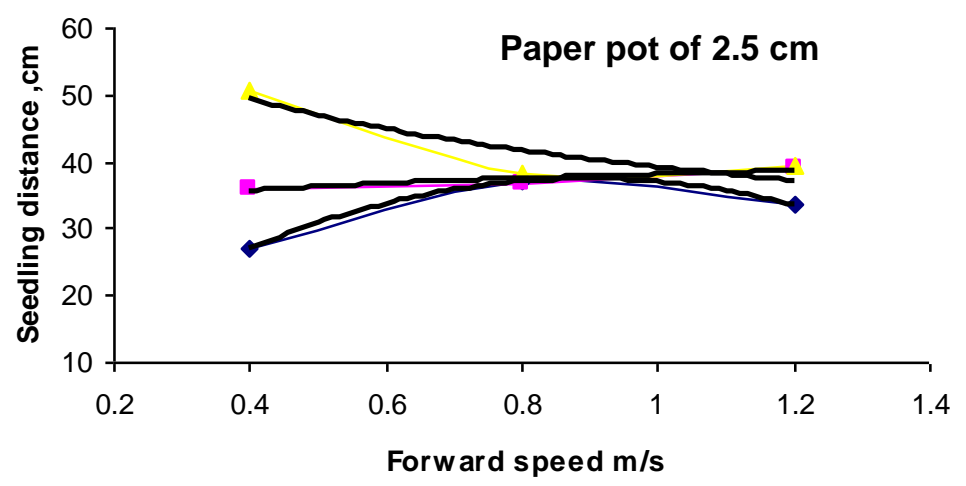

Fig.(4): Effect of forward speed on the average distance between seedlings in row at different roller press diameters

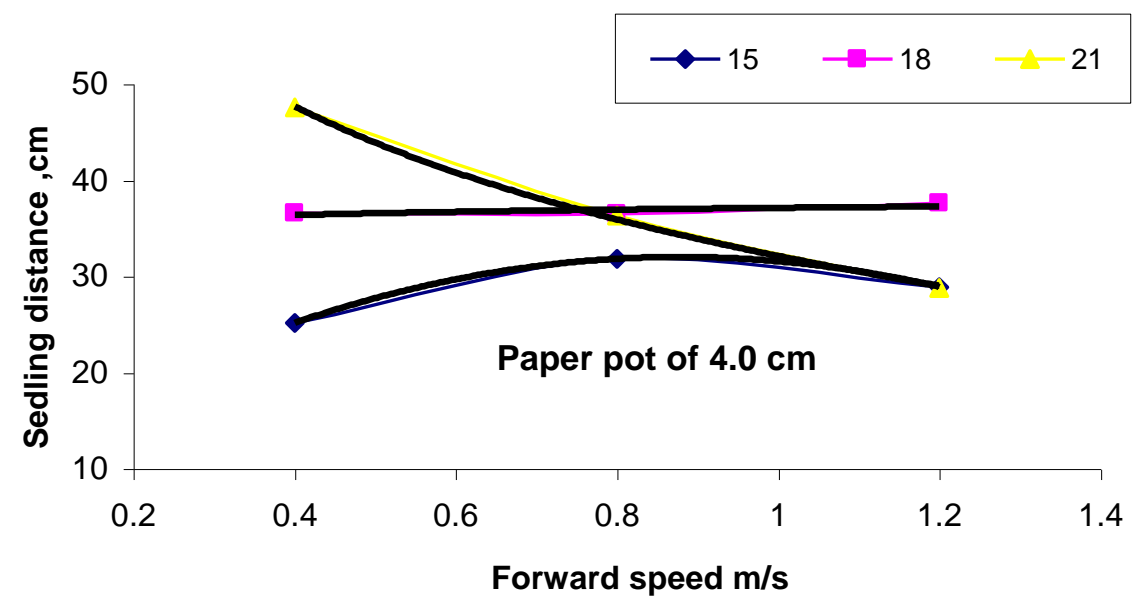

Fig.(5): Effect of forward speed on the average distance between seedlings in row at different roller press diameters

Increasing forward speed from 0.4 to $1.16 \mathrm{~m} / \mathrm{s}$ increased seedling dispersion percentage about $13.32 \%$ under seedling location on horizontal belt of $5.0 \mathrm{~cm}$. While increasing seedling location to $7 \mathrm{~cm}$ caused an increase of seedling dispersion from 2.18 under increasing the forward speed to $1.16 \mathrm{~m} / \mathrm{s}$. These results were obtained under paper pot of 2.5 cm.(fig.6). The same trend was shown as seedling dispersion percentage changed from 40.2 to 55.8 by increasing forward speed from 0.4 to 1.16 $\mathrm{m} / \mathrm{s}$ at seedling location of $10 \mathrm{~cm}$. On the other side, increasing seedling 
location speed from 5.0 to $10.0 \mathrm{~cm}$ changed seedling dispersion percentage from 40.2 to 53.8 at the same conditions. Medium forward speeds of $0.8 \mathrm{~m} / \mathrm{s}$ with different seedling location distance of 5.0; 7.0 and $10,0 \mathrm{~cm}$ for both paper pot diameters of 2.5 and 4.0 showed similar results and gave the same trend on figures.

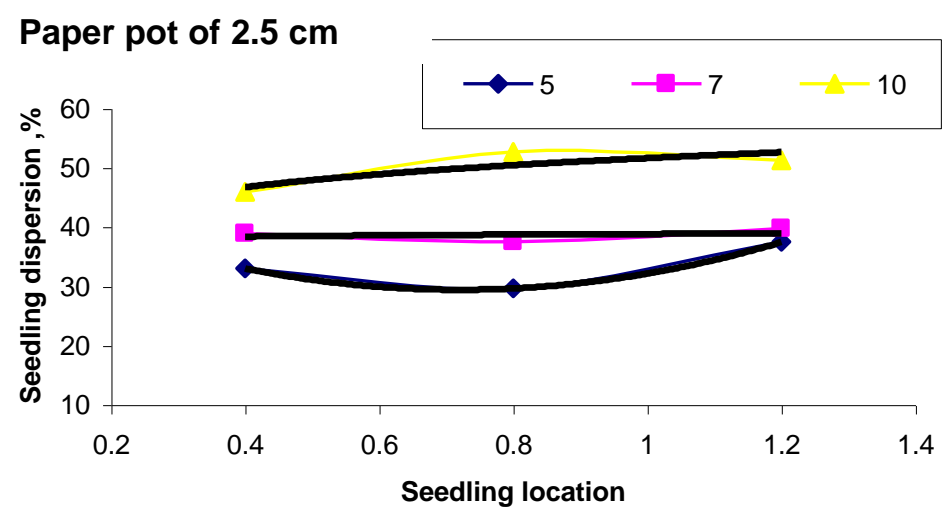

Fig. (6): Effect of seedling location on the seedlings dispersion, \%.

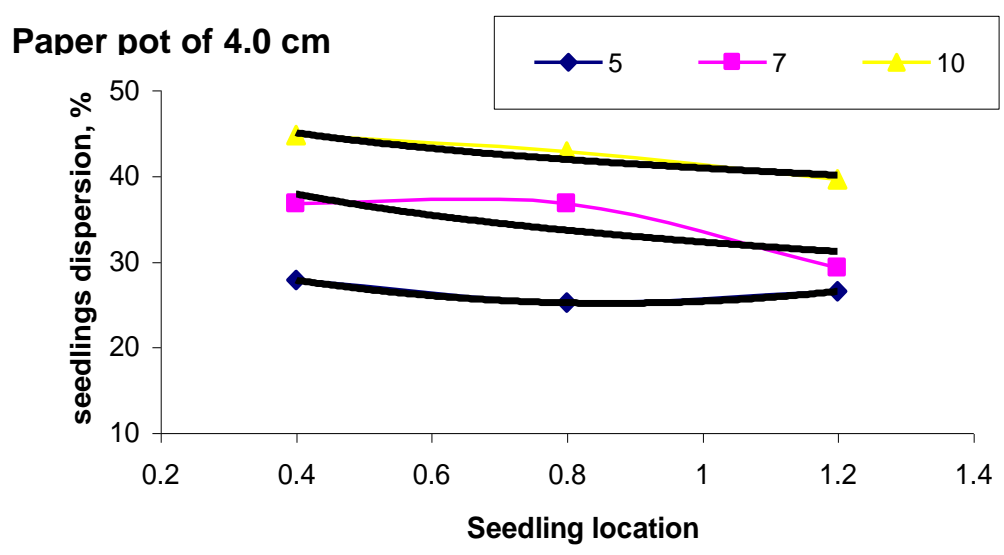

Fig. (7): Effect of seedling location on the seedlings dispersion, \%

Shortly, under seedling location distance of $7.0 \mathrm{~cm}$, the lowest values of seedling dispersion percentage of $12.3 \%$ was achieved under forward speed of $0.8 \mathrm{~m} / \mathrm{s}$ at metering speed of $25 \mathrm{rpm}$. Meanwhile, the highest value was $73.9 \%$ was under forward speed (V) of 1.16 and metering speed $(\mathrm{R})$ of $35 \mathrm{rpm}$; while by changing the seedling location from 7.0 to 
$10 \mathrm{~cm}$ to the highest value of seedling dispersion $10.3 \%$ was obtained under forward speed of $1.16 \mathrm{~m} / \mathrm{s}$ with metering speed of 35rpm. (fig.7) Analysis of variance was also employed to test the difference of seedling location with different forward speeds under different paper pot diameters. This analysis indicated a highly significant difference of engineering parameters under study with all treatments (table-1).

From the above table, the total mean effect of the roller press wheel on the seedling of sugar beat deposition in row are found at the roller press of $21 \mathrm{~cm}$ follow by $18 \mathrm{~cm}$ and the low effect is the roller press of $15 \mathrm{~cm}$ diameter. While the transplanted speed for any seedling speed is more significant. The best values were found at $15 \mathrm{~cm}$ rolling press wheel, 0.4 $\mathrm{m} / \mathrm{s}$ transplanting speed, seedling location distance of $7 \mathrm{~cm}$ and paper pot diameters of $4.0 \mathrm{~cm}$.

\section{3- Effect of seedling location on seed spacing uniformity at different rolling press}

The data of distance between seedlings (spacing uniformity, \%) of sugar beet seedling for relationship between seedling locations at different rolling press were summarized and plotted in figure (8).

Table (1): the analysis of dependent Variable in lab test

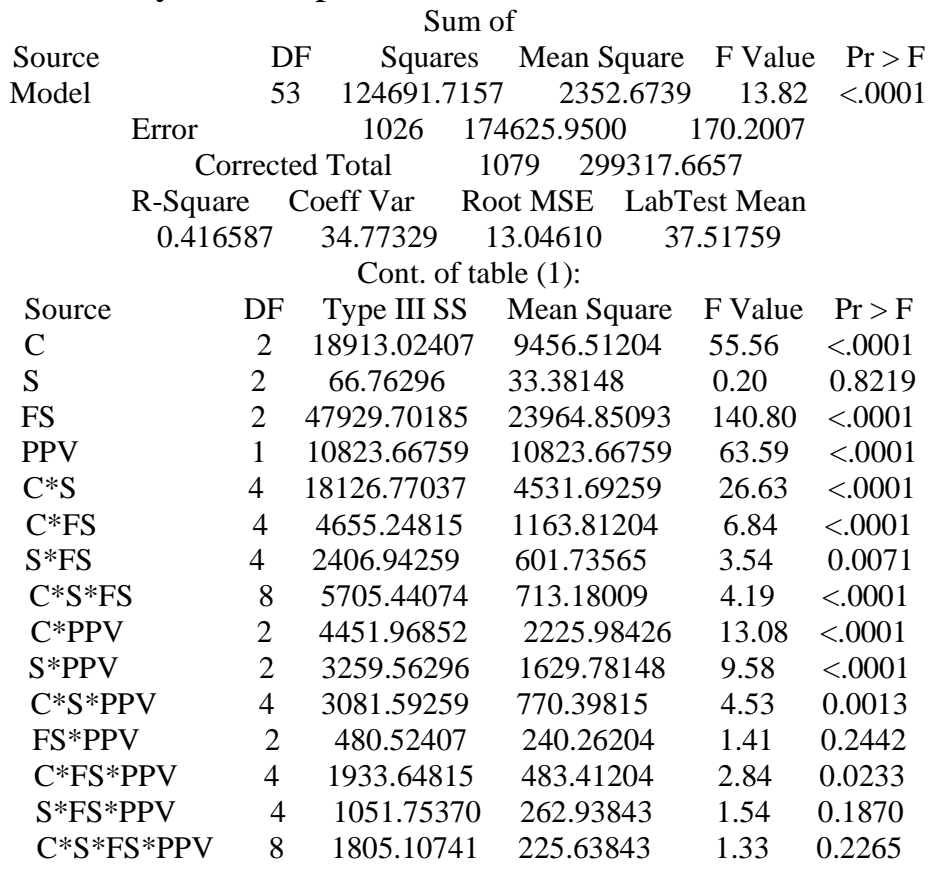


They clearly show that, the average of distance between seedlings percentage with all treatments decreased by increasing each of seedling location and rolling press of feeding systems The distance between seedlings was more uniform with lower distance between seedling location on the horizontal feeding belt and lower transplanting speed and consequently higher planting speeds resulted in more skips, higher speed placement errors and higher average spacing. It is obvious that, increasing seedling location from $7 \mathrm{~cm}$ to $10 \mathrm{~cm}$ resulted in increasing seedling spacing uniformity from 27.5 to $45.3 \%$ at forward speed of $0.4 \mathrm{~m} / \mathrm{s}$ and the press diameter $15 \mathrm{~cm}$. Meanwhile, increasing the press wheel diameter from 15 to $21 \mathrm{~cm}$ resulted in increasing the seedling uniformity by about $13.6 \%$ at 10 seedling location.

\section{4- Effect of transplanter speed on seedling miss index}

The figs (9) showed the effect of transplanting speed on seedling miss index $\left(\mathrm{S}_{\mathrm{mi}}\right)$. Staring directly to the shown figure, it is easy to notice that increasing transplanting speed resulted in increasing seedling miss index percentage (directly proportion). Also, the above relationship indicated that there were a higher significant. Increasing the transplanting speed the $\mathrm{S}_{\mathrm{mi}}$ increased for all treatment, but the less value was found at $0.9 \mathrm{~m} / \mathrm{s}$ traveling speed and $2.5 \mathrm{~cm}$ paper pot diameters. Analytically, press wheel diameter had no effect on seedling miss index percentage $\left(S_{\mathrm{mi}}\right)$ as no correlation between transplanting speed and seedling location.

These were logical results as increasing seedling speed (SR) affected speed of feeding system. This high motion of the translated belts may cause seedling voided in feeder disc. This shoehorning led to seed void and gave the true obtained results. Multiple regression analysis revealed a highly significant linear relationship was found.

\section{5- Effect of transplanter speed on seedlings multiples index, (Smu \%)}

The figs (10) showed the effect of transplanting speed on seedling multiples index, $\left(\mathrm{S}_{\mathrm{mu}} \%\right)$ at different press wheel diameters $(15,15$, and $21 \mathrm{~cm})$. Staring directly to the shown figure, it is easy to notice that increasing transplanting speed resulted in decreasing seedling multiples index, $\left(\mathrm{S}_{\mathrm{mu}} \%\right)$ in percentage (inversely proportion). Also, the above relationship indicated that there were a higher significant. Increasing the 
transplanting speed the seedling multiples index, $\left(\mathrm{S}_{\mathrm{mu}} \%\right)$ decreased for all treatment, but the less value was found at $1,16 \mathrm{~m} / \mathrm{s}$ traveling speed and $21 \mathrm{~cm}$ roll presses diameters. Analytically, paper pot diameter had no effect on seedling multiples index percentage $\left(\mathrm{S}_{\mathrm{mu}} \%\right)$ as no correlation between transplanting speed and seedling location.

Roller press diameter, $\mathrm{mm}$

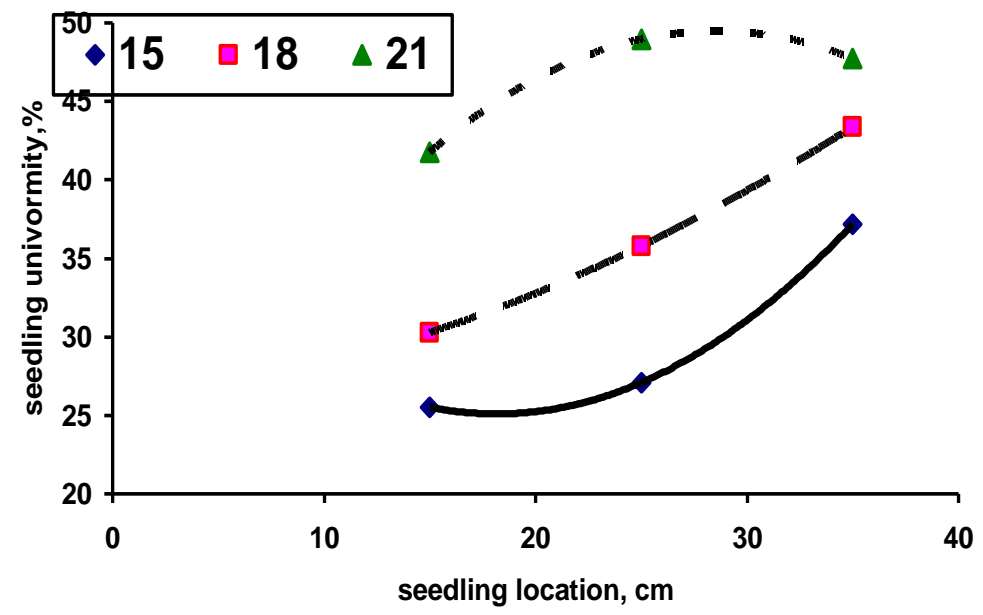

Fig. (8): Effect of seedling location on seedling uniformity, \%

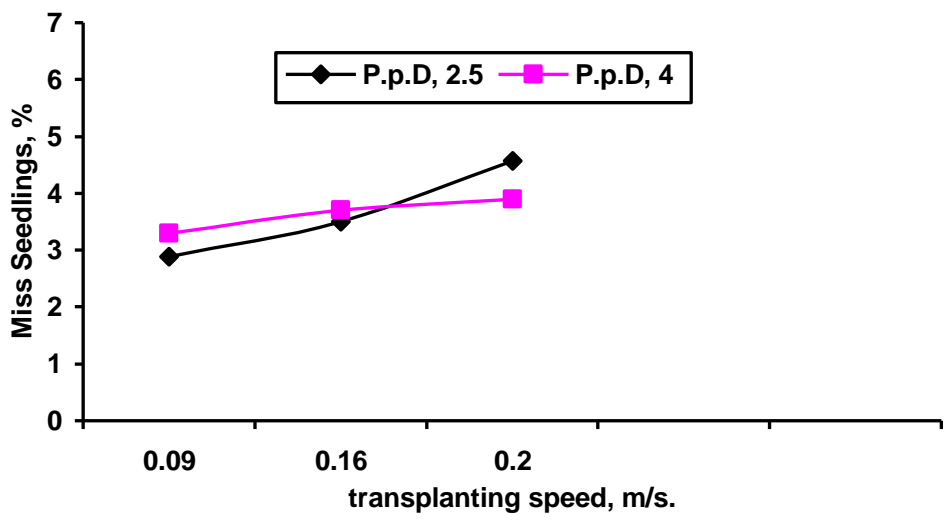

Fig (9): Effect of transplanting speed, $\mathrm{m} / \mathrm{s}$ on miss seedlings. 


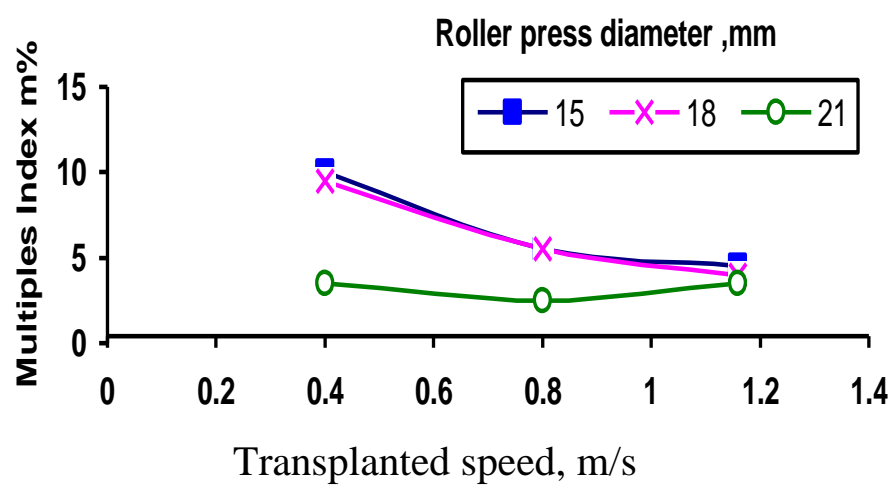

Fig (10): Effect of transplanting speed, $\mathrm{m} / \mathrm{s}$ on seedling multiples index. These were logical results as increasing seedling speed (SR) affected speed of feeding system numbers. This high motion of the translated belts may cause seedling to decrease in feeder disc. This shoehorning led to seed multiples and gave the true obtained results. Multiple regression analysis revealed a highly significant linear relationship was found.

\section{6- The amount of seedling rate (Filed capacity and field efficiency)}

Figs. (11) and (12) illustrate the relationship between field capacity and field efficiency at press wheel diameters and different machine forward speed. Fig. (11) Shows the effect of press wheel diameter on actual field capacity. From the figure the increasing in transplanting speeds from 1.44 to $4.18 \mathrm{~km} / \mathrm{h}$ the actual field capacity increased from about 0.25 to 0.57 fed./h. Then the press wheel diameter for transplanting of $15 \mathrm{~cm}$ increment about $0.47 \mathrm{fed} . / \mathrm{h}$ when compared with the press wheel of $21 \mathrm{~cm}$.

On the other wise, Fig. (12) clarify that the field efficiency of seedlings transplanter machine decreased by increasing forward speed for all press wheel under studies. The maximum field efficiency of $94.5 \%$ was obtained at forward speeding of $1.5 \mathrm{~km} / \mathrm{h}$ and the minimum field efficiency of $83.2 \%$ was obtained at forward speed of $4.2 \mathrm{~km} / \mathrm{h}$.

\section{REFERENCES}

ASAE Standards (1989). Agricultural machinery management, EP 391.1 and D 230, USA: 4.

F.A.O. Statistics devision, ( 10th October 2006)

Hamad, S.A.; M.A. Ali; M. Khalifa and Z.E. Ismail (1983). Manual feeding rice transplanter, J. Agric. Sc. Univ. of Mansoura, 8 (1): 6080. 


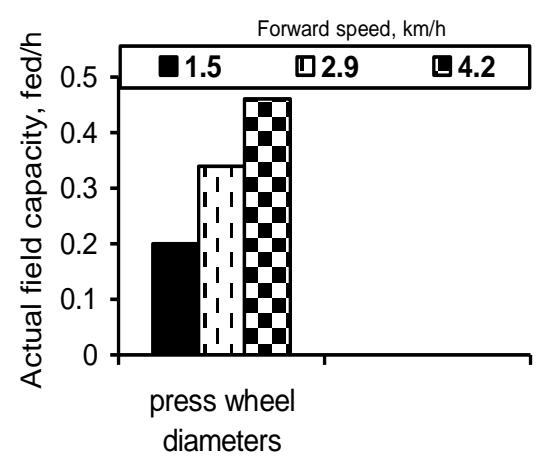

Fig. 11: Effect of transplanting methods on actual field capacity.

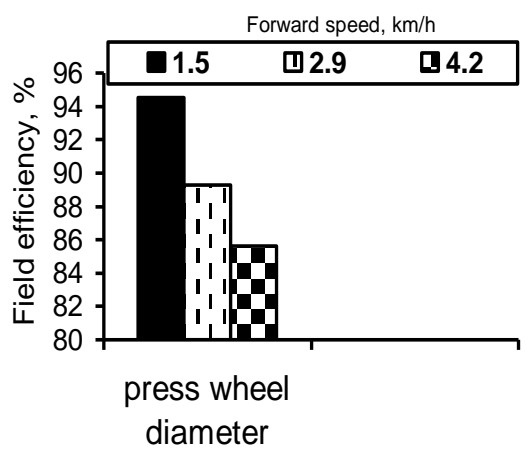

Fig. 12: Effect of transplanting methods on field efficiency.

Harb, S.K. Abdelmawala, H.A. and G.M. Salama (1993). Comparison between mechanical and manual transplanting of tomato. Minia J. of Agric. Res. and Develiop., Special Issue, (15): 361-375.

Helmy, M.A.; E.M. Khalifa; H.M. Sorour and W.A. Gad (2000).Performance evaluation of some

Sugar beet planting machines . Misr J. Ag. Eng., 17 (3): 660-674.

Mortada, K. (2002). National Project of Damsis Planting for Fighting Pelharacia and Fashiola, Ministry of Ag., 3-12.

Ismail , Z .E .and M . A . El sheKha (1989). The theoretical feeding system of transplantier system Misr J. Ag. Eng., 6 ( 3) 237 - 248 .

Odigbah, E.U. and C.O. Akubuo (1991) A two-row automatic mini sett yam planter J. of Agric. Eng. Res., 50 : 189 -196.

Saleh, F.K. (1990). Mechanization of onion Planting. M.Sc. Th., Fac. of Ag., Mansoura Univ., 18-31.

Serivastava, A.K.; C-E Goering and R.P. Rohrbach (1993). "Engineering principles of agricural machines." ASAE TEXT book Number 6. Published by the American Society of Agricultural Engineers PP.255-260.

Tamatsu Miura (1982). Rice transplanting facilities for the raising of seedling. Rice in Japanbooks, 1(2): 80 -94 . 


\section{الملخص العربيى}

\section{در اسة على ميكنة شتل محصول بنجر السكر}

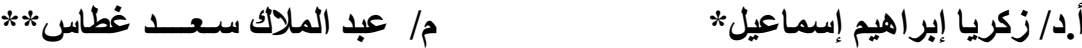

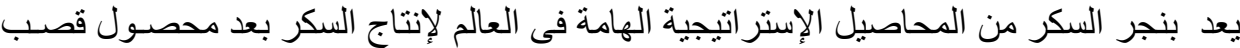

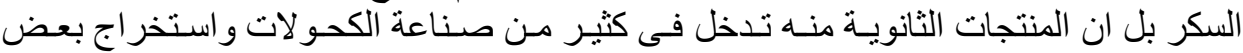

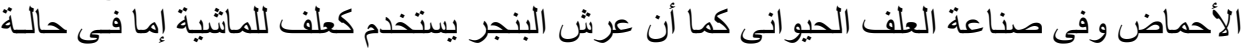

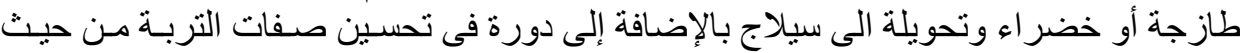

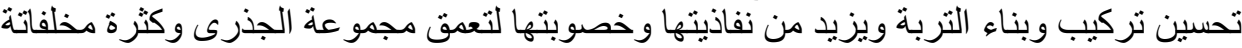

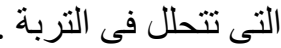

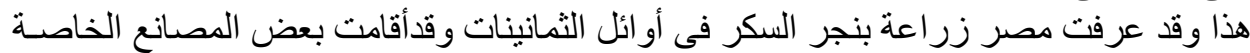

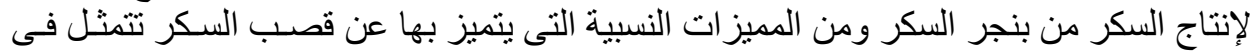

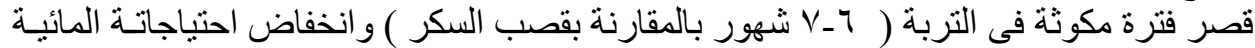

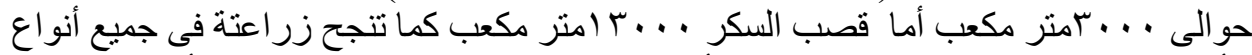

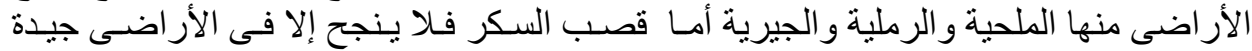

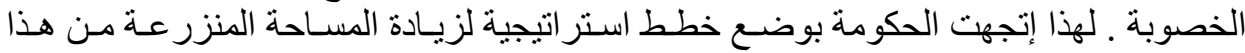

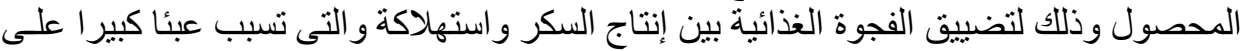

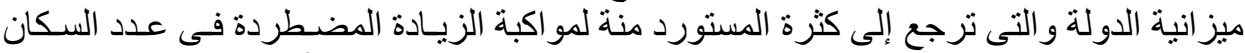

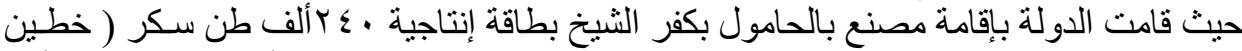

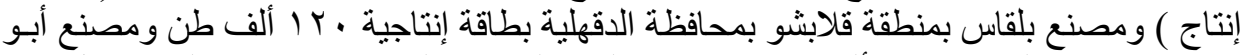

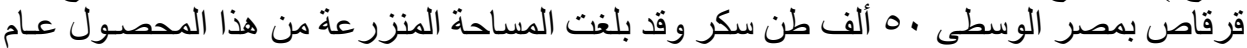

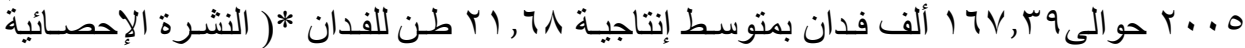

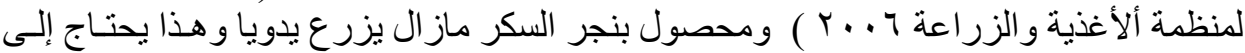

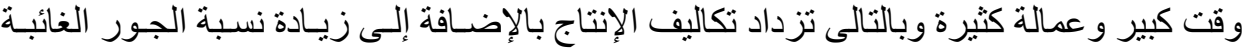

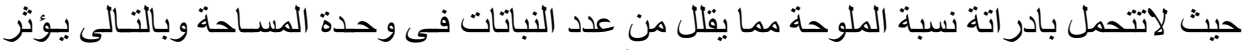

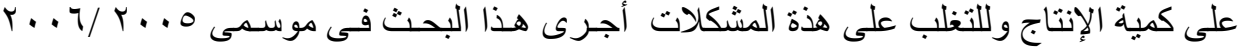

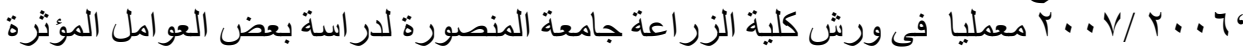

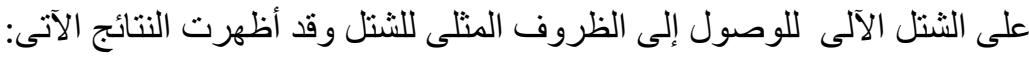

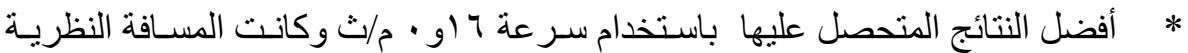

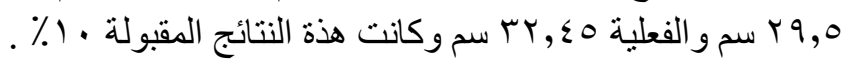

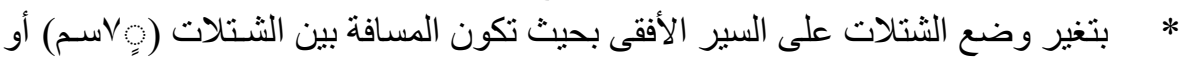

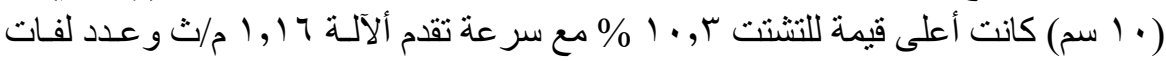

هب لفة /دقيقة . العانت

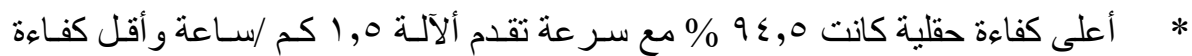

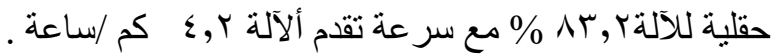

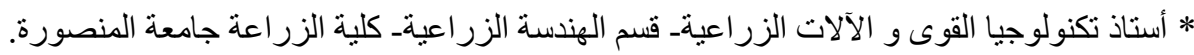
*** دراسات عليا (دكتور اة) - قسم الهندسة الزر اعيةـ كلية الزر اعة جامعة المنصورة. 